\title{
Apnea Testing for the Determination of Brain Death in Patients Supported by Extracorporeal Membrane Oxygenation
}

\author{
Murad Talahma $^{\mathrm{a}, \mathrm{b}}$, Michael Degeorgia ${ }^{\mathrm{a}}$
}

\begin{abstract}
The neurological criteria for brain death include coma, absent brain stem reflexes, and apnea. For patients on extracorporeal membrane oxygenation (ECMO), routine apnea testing is not possible because gas exchange occurs entirely through the membrane oxygenator. We describe the protocol we used to perform the apnea test and declare brain death in a patient on ECMO and review the literature of brain death testing in patients on ECMO. A 39-year-old female presented with cardiogenic shock followed by pulseless electrical activity (PEA) and eventually started on veno-arterial (VA) ECMO. Neurology was consulted for prognostication. Initial exam 48 hours after arrest showed absent brain stem reflexes. Another neurological exam 72 hours after arrest was compatible with brain death, so apnea test was performed. The apnea test involved preoxygenation, then she was disconnected from ventilator and the gas sweep rate decreased to $1 \mathrm{~L} /$ minute while maintaining the same blood flow rate. At 10 minutes, the $\mathrm{PCO}_{2}$ level needed to declare brain death was achieved. With increasing use of ECMO to support critically ill patients, physicians should become familiar with the challenges this technology has created when testing for apnea in the determination of brain death. In this case report, we showed that apnea testing can be done in patients on ECMO without the need for ancillary testing. The mainstay of performing apnea testing on these patients is decreasing the gas sweep rate to $0.5-1 \mathrm{~L} /$ minute while maintaining the same blood flow rate.
\end{abstract}

Keywords: ECMO; Brain death; Apnea test

\section{Introduction}

The neurological criteria for brain death include coma, absent brain stem reflexes, and apnea. Apnea testing involves discon-

\footnotetext{
Manuscript accepted for publication February 26, 2016

aUniversity Hospitals Case Medical Center, Cleveland, OH, USA

${ }^{b}$ Corresponding Author: Murad Talahma, University Hospitals Case Medical Center, 11100 Euclid Ave., Cleveland, OH 44106, USA.

Email:mmmtalahma@gmail.com
}

doi: http://dx.doi.org/10.14740/jnr376w necting the mechanical ventilator, observing for spontaneous respirations and, if none, measuring the $\mathrm{PaCO}_{2}$ after $8-10$ min. The test is positive if the $\mathrm{PaCO}_{2}$ is $\geq 60 \mathrm{~mm} \mathrm{Hg}$ or has increased $\geq 20 \mathrm{~mm} \mathrm{Hg}$ above the baseline. For patients on extracorporeal membrane oxygenation (ECMO), an advanced form of life support, this kind of apnea testing is not possible because gas exchange occurs entirely through the membrane oxygenator. ECMO provides oxygenation and circulatory support for patients with severe respiratory and cardiac failure. A modification of the cardiopulmonary bypass circuit is routinely used in cardiac surgery; ECMO is smaller and portable and can be used for several days to weeks in adult respiratory distress syndrome, cardiogenic shock, as a bridge to heart or lung transplantation [1], or to support in-hospital cardiac arrest [2-4]. Though early use of ECMO in the 1970s was plagued with complications $[5,6]$, advances in technology and safety have resulted in its increasing use over the last decade [7-10].

\section{Configuration of the ECMO circuit}

There are two configurations with ECMO: a veno-venous (VV) configuration to provide oxygenation in patients with respiratory failure and a veno-arterial (VA) configuration to provide both oxygenation and circulation in patients with respiratory and cardiac failure [11] (Fig. 1). For both, the circuit is composed of vascular access catheters and heparin coated tubing, a blood pump, membrane oxygenator and a temperature control system. In VV ECMO, de-oxygenated blood is removed from a venous catheter placed in the femoral vein (extending into the inferior vena cava) and passively drained by gravity into a reservoir. A pump then either pushes (using a roller pump) or draws (using a centrifugal pump) the blood from the reservoir and through a membrane oxygenator and heat exchanger before returning to the internal jugular vein (extending into the right atrium) [12] (Fig. 2).

Typically, the membrane oxygenator is manufactured with microporous polypropylene material to create hollow, capillary fibers or capillary membranes, which provide a blood-gas interface for the diffusion of gases. Specifically, blood flows inside the capillary fibers while gas flows outside in the opposite direction. The composition of the gas on the gas side of the oxygenator membrane is determined by adjustment of a blender that mixes room air with oxygen for delivery into the 


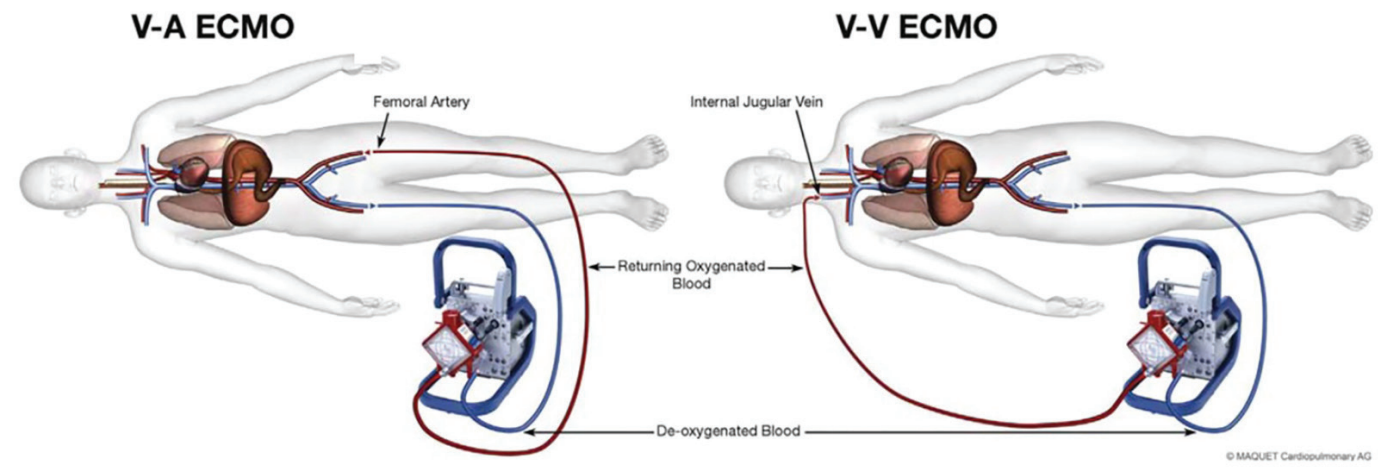

Figure 1. Illustration of VA ECMO and VV ECMO. Example of the cannulation sites for VA ECMO (femoral vein-femoral artery) and VV ECMO (femoral vein-internal jugular vein) with blood flow through the oxygenator.

oxygenator. The membrane oxygenator acts as the "artificial lung" adding oxygen $\left(\mathrm{O}_{2}\right)$ and removing carbon dioxide $\left(\mathrm{CO}_{2}\right)$ from the blood. That is, though patients are usually mechanically ventilated, because venous blood is being diverted away from the lungs and through the membrane oxygenator, adjusting the ventilator settings will not affect the $\mathrm{PaO}_{2}$ or $\mathrm{PaCO}_{2}$. Oxygenation is determined mainly by the fraction of oxygen delivered through the oxygenator and rate of blood flow through the circuit. Clearance of $\mathrm{CO}_{2}$ depends mainly on the rate of sweep gas flow through the oxygenator [13]. Because of the high solubility and fast diffusion property of $\mathrm{CO}_{2}$, removal is very efficient and can occur at lower blood flow rates needed for adequate oxygenation.

For VA ECMO, it is the same process just that the blood is returned to the femoral artery. Initial cardiac output targets of $1.5-2.0 \mathrm{~L} / \mathrm{min}$ are acceptable but are titrated up gradually to
3.0 - $6.0 \mathrm{~L} / \mathrm{min}$. Because arterial flow will be continuous and non-pulsatile, a pulse pressure of approximately $10-15 \mathrm{~mm}$ $\mathrm{Hg}$ is considered acceptable [14]. Though usually not necessary, sometimes vasopressors and inotropic agents can be used to achieve a specific target blood pressure and cardiac output (VV ECMO does not support the circulation and thus has no effect on cardiovascular hemodynamics) (Table 1) [15].

\section{Brain death}

The neurological criteria for brain death were defined by the American Academy of Neurology Practice Parameter in 1995 [16] and updated in 2010 [17]. They include the following clinical prerequisites: irreversible and proximate cause of coma documented by either clinical or neuroimaging evidence

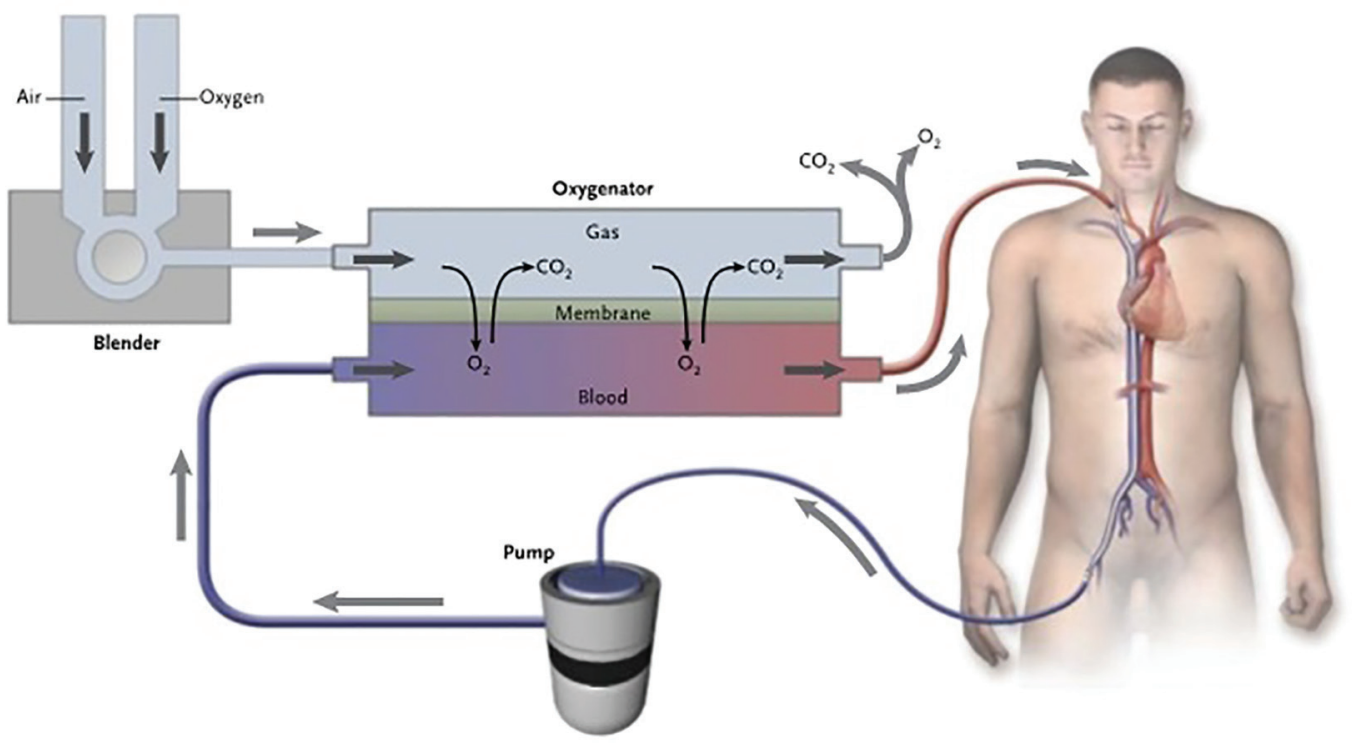

Figure 2. The membrane oxygenator in ECMO. The extracorporeal membrane oxygenation pump delivers venous blood to the oxygenator. This device is divided into two chambers by a semipermeable membrane. The venous blood enters the oxygenator and travels along one side of the membrane (the blood side), while fresh gas known as sweep gas is delivered to the other side (the gas side). Gas exchange (oxygen uptake and carbon dioxide elimination) takes place across the membrane. The oxygenated blood reinfused into the patient's venous system. 
Table 1. The Standard Initial Settings and Goals for ECMO [15]

\begin{tabular}{ll}
\hline Circuit flow & $50-80 \mathrm{~mL} / \mathrm{kg} / \mathrm{min}$ \\
Sweep gas flow & $50-80 \mathrm{~mL} / \mathrm{kg} / \mathrm{min}$ \\
\hline Fractional inspired oxygen & $100 \%$ \\
Oxygen saturation (drainage cannula) & $>65 \%$ \\
Oxygen saturation (return cannula) & $100 \%$ \\
Arterial oxygen saturation & $\mathrm{VA}:>95 \% ; \mathrm{VV}: 85-92 \%$ \\
Arterial carbon dioxide tension & $35-45 \mathrm{~mm} \mathrm{Hg}$ \\
Mean arterial pressure & $65-95 \mathrm{~mm} \mathrm{Hg}$ \\
\hline
\end{tabular}

of catastrophe along with exclusion of confounding factors that could be contributing to coma such as severe electrolyte, acid base, or endocrine abnormities, CNS-depressant drugs, hypothermia (core temperature $<36^{\circ} \mathrm{C}$ ) and hypotension (systolic blood pressure $<100 \mathrm{~mm} \mathrm{Hg}$ ). In adults, a single careful neurological examination is required to document the presence of coma and the absence of brain stem reflexes. After that an apnea test is performed to document the absence of spontaneous respirations. First, a baseline arterial blood gas is obtained to ensure eucapnea and then the patient is removed from the mechanical ventilator and observed for any evidence of spontaneous respirations. If no respirations are observed, a repeat blood gas is obtained after approximately $8 \mathrm{~min}$. The test is considered positive if the $\mathrm{PaCO}_{2}$ is $\geq 60 \mathrm{~mm} \mathrm{Hg}$ or has increased at least $20 \mathrm{~mm} \mathrm{Hg}$ above the baseline $\mathrm{PaCO}_{2}$. The time of death is declared to be the time the $\mathrm{PaCO}_{2}$ reached the target value.

For patients with severe respiratory or cardiac failure supported on ECMO, the practice parameter does not provide a process for apnea testing. Unlike patients on mechanical ventilation alone, gas exchange for patients supported on ECMO occurs mainly through the membrane oxygenator. Carbon dioxide elimination is dependent on the sweep gas flow rate.

We report a patient who met the neurological criteria for brain death but because of ECMO, an apnea test could not be performed in the typical manner. We describe the process we used to perform the apnea test and declare brain death and review the literature of brain death testing for patients on ECMO.

\section{Case Report}

A 39-year-old woman with systemic lupus erythematosus was found unresponsive at home following a brief febrile illness. She was found to be on cardiogenic shock suspected to be secondary to fulminant myocarditis. Shortly after admission, she had a pulseless electrical activity (PEA) cardiac arrest. An attempt at resuscitation followed for the next $40 \mathrm{~min}$, which included sternotomy, open heart massage, and eventually VA ECMO support. Therapeutic hypothermia was begun. After 24 $\mathrm{h}$, the patient was taken to the operating room for a cardiac washout and was found to have no evidence of cardiac activity even when electrically paced. She was rewarmed, sedation was stopped and the following day ( $48 \mathrm{~h}$ after the event), the neurology service was consulted for evaluation and prognostication.

The initial examination found her to be normothermic (temperature of $36.5^{\circ} \mathrm{C}$ ) and normotensive (mean arterial pressure (MAP): $70 \mathrm{~mm} \mathrm{Hg}$ ). She was comatose. Brain stem examination revealed bilateral fixed and dilated pupils, absent cough and gag reflexes and absent corneal reflex. Eyes were midline and showed no reflexive movement to head turning (Doll's eyes maneuver) or to cold water irrigation into the ears (cold calorics or oculo-vestibular reflex). Motor examination showed no movement of the limbs to noxious stimulation. The physical examination was repeated the following day ( $72 \mathrm{~h}$ after the vent and $24 \mathrm{~h}$ off sedation). Her neurological examination was identical. Because she was being supported with VA ECMO, certain adjustments were required to perform an apnea test.

Her initial VA ECMO settings were blood flow rate $5 \mathrm{~L} /$ min, $\mathrm{FiO}_{2} 70 \%$, and gas sweep flow rate $4 \mathrm{~L} / \mathrm{min}$. Her MAP was $70 \mathrm{~mm} \mathrm{Hg}$. First, preoxygenation was done for $10 \mathrm{~min}$ by increasing the $\mathrm{FiO}_{2}$ on the membrane oxygenator to $100 \%$. A baseline arterial blood gas showed $\mathrm{pH} 7.33, \mathrm{PaCO}_{2} 47 \mathrm{~mm} \mathrm{Hg}$, and $\mathrm{PaO}_{2} 535 \mathrm{~mm} \mathrm{Hg}$. Second, the gas sweep flow rate was reduced to $1 \mathrm{~L} / \mathrm{min}$ and the mechanical ventilator was disconnected. The patient was observed for any evidence of spontaneous respirations. A repeat arterial blood gas at $5 \mathrm{~min}$ showed $\mathrm{pH} 7.30, \mathrm{PaCO}_{2} 50 \mathrm{~mm} \mathrm{Hg}$, and $\mathrm{PaO}_{2} 185 \mathrm{~mm} \mathrm{Hg}$. Another arterial blood gas at 10 min showed $\mathrm{pH} 7.20, \mathrm{PaCO}_{2} 65 \mathrm{~mm} \mathrm{Hg}$, and $\mathrm{PaO}_{2} 444 \mathrm{~mm} \mathrm{Hg}$. During the 10-min period disconnected from the ventilator, no spontaneous respiration was observed. After reaching the $\mathrm{PaCO}_{2}$ target and with no evidence of respiratory drive, the patient was declared brain dead.

\section{Discussion}

\section{Apnea testing in brain death}

Apnea, the absence of spontaneous breathing, is an essential criterion for the diagnosis of brain death. Various methods of performing an apnea test have been recommended. In the original landmark Harvard report from Beecher and colleagues in 1968, apnea was defined as absent spontaneous breathing for 3 min after discontinuation of the mechanical ventilator. In the cerebral survival study done from 1970 to 1972, apnea was defined as a lack of respiratory effort to override the ventilator for 15 min. In 1978, Schafer and colleagues suggested for the first time a specific $\mathrm{PaCO}_{2}$ threshold to determine apnea. That is, in order to definitively confirm apnea, the $\mathrm{PaCO}_{2}$ level must be high enough to ensure supramaximal stimulation of the medullary respiratory centers. To determine what that threshold was, 10 patients who otherwise met the clinical criteria for brain death were disconnected from the ventilator and the $\mathrm{PaCO}_{2}$ was serially measured. Spontaneous resumption of breathing occurred in three of the 10 patients. The authors wrote, "the highest respiratory threshold or apnea point we measured was a $\mathrm{PaCO}_{2}$ of $56 \mathrm{~mm} \mathrm{Hg}$. Therefore it appears safe to conclude that apnea is absolute when a $\mathrm{PaCO}_{2}$ of $60 \mathrm{~mm} \mathrm{Hg}$ cannot stimulate spontaneous breathing." This forms the basis of 
Table 2. Summary of ECMO Settings During Apnea Testing [21-25]

\begin{tabular}{|c|c|c|c|c|c|}
\hline Report & Case & Initial ECMO settings & $\begin{array}{l}\text { Oxygenation } \\
\text { method }\end{array}$ & ECMO during testing & Ancillary testing \\
\hline \multirow[t]{2}{*}{ Jarrah et al [21] } & $\# 1$ & $\begin{array}{l}\text { Blood flow rate } 88 \mathrm{~mL} / \mathrm{kg} / \mathrm{min} \\
\text { Sweep flow rate } 0.5 \mathrm{~L} / \mathrm{min} \\
\mathrm{FiO}_{2} 100 \%\end{array}$ & $\begin{array}{l}\text { CPAP } \\
\mathrm{FiO}_{2} 100 \%\end{array}$ & $\begin{array}{l}\text { Blood flow rate } 88 \mathrm{~mL} / \mathrm{kg} / \mathrm{min} \\
\text { Sweep flow rate } 0.1 \mathrm{~L} / \mathrm{min} \\
\mathrm{FiO}_{2} 100 \%\end{array}$ & None \\
\hline & $\# 2$ & $\begin{array}{l}\text { Blood flow rate } 38 \mathrm{~mL} / \mathrm{kg} / \mathrm{min} \\
\text { Sweep flow rate } 5.5 \mathrm{~L} / \mathrm{min} \\
\mathrm{FiO}_{2} 100 \%\end{array}$ & $\begin{array}{l}\text { CPAP } \\
\mathrm{FiO}_{2} 100 \%\end{array}$ & $\begin{array}{l}\text { Blood flow rate } 38 \mathrm{~mL} / \mathrm{kg} / \mathrm{min} \\
\text { Sweep flow rate } 1.0 \mathrm{~L} / \mathrm{min} \\
\mathrm{FiO}_{2} 100 \%\end{array}$ & None \\
\hline Hoskote et al [24] & & $\begin{array}{l}\text { Blood flow rate } 4.5 \mathrm{~mL} / \mathrm{kg} / \mathrm{min} \\
\text { Sweep flow rate } 6 \mathrm{~L} / \mathrm{min} \\
\mathrm{FiO}_{2} 100 \%\end{array}$ & None & $\begin{array}{l}\text { Blood flow rate } 4.5 \mathrm{~mL} / \mathrm{kg} / \mathrm{min} \\
\text { Sweep flow rate } 0.5 \mathrm{~L} / \mathrm{min} \\
\mathrm{FiO}_{2} 100 \%\end{array}$ & None \\
\hline \multirow[t]{2}{*}{ Goswami et al [25] } & \#1 & $\begin{array}{l}\text { Blood flow rate } 5.0 \mathrm{~mL} / \mathrm{kg} / \mathrm{min} \\
\text { Sweep flow rate Not documented } \\
\mathrm{FiO}_{2} 100 \%\end{array}$ & Not specified & $\begin{array}{l}\text { Blood flow rate } 5.0 \mathrm{~mL} / \mathrm{kg} / \mathrm{min} \\
\text { Sweep flow rate } 0.5 \mathrm{~L} / \mathrm{min} \\
\mathrm{FiO}_{2} 100 \%\end{array}$ & EEG \\
\hline & $\# 2$ & $\begin{array}{l}\text { Blood flow rate } 4.1 \mathrm{~mL} / \mathrm{kg} / \mathrm{min} \\
\text { Sweep flow rate } 3 \mathrm{~L} / \mathrm{min} \\
\mathrm{FiO}_{2} 40 \% \text { increased to } 100 \% \\
\text { during preoxygenation }\end{array}$ & Not specified & $\begin{array}{l}\text { Blood flow rate } 6.0 \mathrm{~mL} / \mathrm{kg} / \mathrm{min} \\
\text { Sweep flow rate } 0.5 \mathrm{~L} / \mathrm{min} \\
\mathrm{FiO}_{2} 100 \%\end{array}$ & EEG \\
\hline Iannuzzi et al [23] & & $\begin{array}{l}\text { Blood flow rate } 4.0 \mathrm{~mL} / \mathrm{kg} / \mathrm{min} \\
\text { Sweep flow rate } 8 \mathrm{~L} / \mathrm{min} \\
\mathrm{FiO}_{2} 70 \%\end{array}$ & $\begin{array}{l}\text { CPAP } \\
\mathrm{FiO}_{2} 100 \%\end{array}$ & $\begin{array}{l}\text { Blood flow rate } 2.0 \mathrm{~mL} / \mathrm{kg} / \mathrm{min} \\
\text { Sweep flow rate } 0.5 \mathrm{~L} / \mathrm{min} \\
\mathrm{FiO}_{2} 100 \%\end{array}$ & None \\
\hline
\end{tabular}

the current guidelines, which recommend discontinuing the ventilator for approximately $8 \mathrm{~min}$ after which the $\mathrm{PaCO}_{2}$ is measured again. Because under normal circumstances, without respiration, the $\mathrm{PaCO}_{2}$ rises on average $2.5 \mathrm{~mm} \mathrm{Hg}$ per minute, beginning with a normal $\mathrm{PaCO}_{2}$ of $40 \mathrm{~mm} \mathrm{Hg}$, after 8 min of no respiration, the $\mathrm{PaCO}_{2}$ should be $60 \mathrm{~mm} \mathrm{Hg}$. If the apnea test cannot be performed, the guidelines recommend that an ancillary test be performed.

\section{The apnea test with ECMO}

Performing brain death testing in patients supported by ECMO is challenging because patients are not dependent on the mechanical ventilator for removal of $\mathrm{CO}_{2}$, which is achieved through the membrane oxygenator. There have been few reports in the literature regarding the protocol of brain death testing in patients supported by ECMO. In one review of children who died on ECMO, brain death was determined in $29 \%$ of them but the protocol that was used was not described [18]. In another review of 87 patients on ECMO over an 8-year period, three met criteria for brain death but in two of them, apnea testing was deemed "too difficult to perform" and in the third, support was withdrawn before apnea testing could be done [19]. Hsieh and colleagues reported three patients supported by
ECMO who underwent brain death testing. In their protocol, however, the ECMO oxygenator was turned off and then the ventilator was disconnected. Apnea testing proceeded in the usual manner [20]. There are five additional case reports that described, in varying degrees of detail, protocols used to perform apnea testing in eight patients. All involve maintaining patients on ECMO but decreasing the sweep flow rate in order to cause the $\mathrm{PaCO}_{2}$ to rise above the target of $60 \mathrm{~mm} \mathrm{Hg}$ after which patients were declared brain dead (Table 2) [21-25].

Jarrah and colleagues for example reported three pediatric patients on VA ECMO [21]. After preoxygenating by increasing the ECMO circuit $\mathrm{FiO}_{2}$ to $100 \%$, all were placed on CPAP with $\mathrm{FiO}_{2}$ 100\% administered through a flow-inflating anesthesia bag connected to the endotracheal tube. The blood flow rate was left unchanged while the sweep gas flow rate was decreased. Specifically, the sweep gas flow rate in the first patient, a 2.5-year-old child, was titrated down from a baseline of $0.5 \mathrm{~L} / \mathrm{min}$ to $0.25-0.1 \mathrm{~L} / \mathrm{min}$. No spontaneous respirations were observed and, after $48 \mathrm{~min}$, the $\mathrm{PaCO}_{2}$ reached the target and brain death was declared. In the second patient, a 14-year-old child, the baseline sweep gas flow rate was $5.5 \mathrm{~L} /$ min and was decreased to $1.0 \mathrm{~L} / \mathrm{min}$. The $\mathrm{PaCO}_{2}$ reached the target after $60 \mathrm{~min}$ and no respiratory movements were observed. In the third, a 5-month-old infant, the baseline sweep gas flow rate was $0.2 \mathrm{~L} / \mathrm{min}$ and was decreased to $0.1 \mathrm{~L} / \mathrm{min}$. 


\section{Prerequisites}

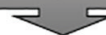

Establish irreversible and proximate cause of coma.

Exclude the presence of a CNS-depressant drug effect.

Exclude or correct any severe electrolyte, acid-base, or endocrine disturbance

Achieve normal core temperature.

Achieve acceptable blood pressure. The patient should have stable MAP preferably $>65 \mathrm{~mm} \mathrm{Hg}$.

Perform one carful neurological exam

No response to noxious stimuli other than spinally mediated reflexes.

All brainstem reflexes, including pupillary response to light, oculocephalic reflex,

oculovestibular reflex, corneal reflex, gag and cough reflexes should be absent.

Perform the Apnea Test

1. Adjust the sweep rate at the ECMO to achieve eucapnia $(\mathrm{PaCO} 235-45 \mathrm{~mm} \mathrm{Hg})$.

2. Perform 10 minutes of preoxygenation by increasing the $\mathrm{FiO} 2$ of the oxygenator

on the ECMO machine to $100 \%$.

3. Disconnect the patient from the ventilator and preserve oxygenation by placing

the cannula in the trachea at the level of the carina and delivering $100 \%$ oxygen at

the rate of $5-8 \mathrm{~L} / \mathrm{min}$.

4. Maintain the same ECMO settings including the blood flow rate and $\mathrm{FiO} 2$ and

gradually decrease the gas sweep rate to as low as $0.5 \mathrm{~L} / \mathrm{min}$ as tolerated by patient

5 . Watch for any sign of respiratory movements including brief gasp.

6. Repeat $A B G$ after 5 minutes and then after 10 minutes.

7. If the required $\mathrm{PaCO} 2$ level is not achieved after 10 minutes, and the patient

remains hemodynamically stable, continue the low gas sweep rate for another 5 minutes and repeat the $\mathrm{ABG}$.

8. The apnea test is considered positive if respiratory movements are absent and

arterial $\mathrm{PCO} 2$ is $>60 \mathrm{~mm} \mathrm{Hg}$ or $20 \mathrm{~mm} \mathrm{Hg}$ increase in arterial $\mathrm{PCO} 2$ over a

baseline.

Figure 3. Steps of performing apnea test in patients on ECMO. Stepwise illustration of performing apnea test to confirm brain death in patients supported by ECMO.

The $\mathrm{PaCO}_{2}$ reached the target after $11 \mathrm{~min}$. In this third patient, EEG was done and showed no evidence of brain electrical activity. Smilevitch and colleagues described a similar approach in a 29-year-old patient on VA ECMO [22]. After preoxygenation by increasing the $\mathrm{FiO}_{2}$ to $100 \%$, the patient was placed on T-piece instead of CPAP and supplemental oxygen delivered at $9 \mathrm{~L} / \mathrm{min}$. The sweep flow rate was then decreased from 4.1 to $1.0 \mathrm{~L} / \mathrm{min}$. The $\mathrm{PaCO}_{2}$ reached the target after $10 \mathrm{~min}$. Two EEGs showed absence of brain electrical activity.

Iannuzzi and colleagues described apnea testing in a 40-year-old patient on a VV ECMO [23]. In their report, both the blood flow rate and the sweep flow rate were decreased. The baseline blood flow rate was $4.0 \mathrm{~L} / \mathrm{min}$ and the sweep flow rate was $8.0 \mathrm{~L} / \mathrm{min}$. The $\mathrm{FiO}_{2}$ was increased to $100 \%$ and the patient was placed on CPAP with $\mathrm{FiO}_{2}$ of $100 \%$ administered through a T-piece. The blood flow rate was then decreased to $2.0 \mathrm{~L} / \mathrm{min}$ and the sweep flow rate to $0.5 \mathrm{~L} / \mathrm{min}$. The $\mathrm{PaCO}_{2}$ reached the target level after 6 min. Finally, in two other case reports, the protocol did not include preoxygenation. In the 58-year-old patient described by Hoskote and colleagues [24], the baseline sweep flow rate was $6.0 \mathrm{~L} / \mathrm{min}$. The ventilator was simply disconnected and the sweep flow rate decreased to $0.5 \mathrm{~L} / \mathrm{min}$. The $\mathrm{PaCO}_{2}$ reached the target level after $9 \mathrm{~min}$. Goswami and colleagues described two patients on VA ECMO [25]. In both, there was no mentioning of the baseline sweep flow rate, but it is mentioned that it was decreased to $0.5 \mathrm{~L} / \mathrm{min}$ during the apnea testing. The $\mathrm{PaCO}_{2}$ reached the target level after $3 \mathrm{~min}$ in the first patient and after $10 \mathrm{~min}$ in the second.

While the rate of $\mathrm{PaCO}_{2}$ rise on ECMO is proportional to the ECMO circuit blood flow and sweep gas flow, there are no clear guidelines in the literature to follow while performing the apnea test on these patients. Yang and colleagues [26] proposed decreasing the sweep gas flow rate to zero during apnea testing but that might make it hard to maintain adequate oxygenation at that level [19]. Thus most people have chosen $0.5-1.0 \mathrm{~L} / \mathrm{min}$ of sweep gas flow during apnea testing as an estimation of the optimal level balance between providing oxygenation and $\mathrm{CO}_{2}$ clearance.

\section{Conclusion}

With increasing use of ECMO to support critically ill patients, physicians should become familiar with the challenges this 
technology has created when testing for apnea in the determination of brain death. Because $\mathrm{CO}_{2}$ clearance is solely dependent on the rate of sweep gas flow through the oxygenator rather than the mechanical ventilator [13], the standard apnea testing protocol of disconnecting the ventilator, observing for spontaneous respirations and measuring the $\mathrm{PaCO}_{2}$ after $8-10$ min, does not apply. Ancillary tests have been suggested as a way to confirm brain death when performing the apnea test is not possible. In this case report, however, we showed that apnea testing can be done in patients on ECMO without the need for ancillary testing. The mainstay of performing apnea testing on these patients is decreasing the gas sweep rate to $0.5-1 \mathrm{~L} /$ min while maintaining the same blood flow rate (Fig. 3). Implementation of such a standardized approach for apnea testing in this patient population is helpful in making the timely diagnosis of brain death.

\section{Conflict of Interest}

The authors declare that they have no conflict of interest.

\section{Abbreviations}

ECMO: extracorporeal membrane oxygenation; VV: venovenous; VA: veno-arterial

\section{References}

1. Abrams D, Combes A, Brodie D. Extracorporeal membrane oxygenation in cardiopulmonary disease in adults. J Am Coll Cardiol. 2014;63(25 Pt A):2769-2778.

2. Chen YS, Chao A, Yu HY, Ko WJ, Wu IH, Chen RJ, Huang SC, et al. Analysis and results of prolonged resuscitation in cardiac arrest patients rescued by extracorporeal membrane oxygenation. J Am Coll Cardiol. 2003;41(2):197-203.

3. Chen YS, Lin JW, Yu HY, Ko WJ, Jerng JS, Chang WT, Chen WJ, et al. Cardiopulmonary resuscitation with assisted extracorporeal life-support versus conventional cardiopulmonary resuscitation in adults with in-hospital cardiac arrest: an observational study and propensity analysis. Lancet. 2008;372(9638):554-561.

4. Cave DM, Gazmuri RJ, Otto CW, Nadkarni VM, Cheng A, Brooks SC, Daya M, et al. Part 7: CPR techniques and devices: 2010 American Heart Association Guidelines for Cardiopulmonary Resuscitation and Emergency Cardiovascular Care. Circulation. 2010;122(18 Suppl 3):S720728.

5. Morris AH, Wallace CJ, Menlove RL, Clemmer TP, Orme JF, Jr., Weaver LK, Dean NC, et al. Randomized clinical trial of pressure-controlled inverse ratio ventilation and extracorporeal $\mathrm{CO} 2$ removal for adult respiratory distress syndrome. Am J Respir Crit Care Med. 1994;149(2 Pt 1):295-305.

6. Zapol WM, Snider MT, Hill JD, Fallat RJ, Bartlett RH,
Edmunds LH, Morris AH, et al. Extracorporeal membrane oxygenation in severe acute respiratory failure. A randomized prospective study. JAMA. 1979;242(20):21932196.

7. Combes A, Bacchetta M, Brodie D, Muller T, Pellegrino V. Extracorporeal membrane oxygenation for respiratory failure in adults. Curr Opin Crit Care. 2012;18(1):99-104.

8. Khoshbin E, Roberts N, Harvey C, Machin D, Killer H, Peek GJ, Sosnowski AW, et al. Poly-methyl pentene oxygenators have improved gas exchange capability and reduced transfusion requirements in adult extracorporeal membrane oxygenation. ASAIO J. 2005;51(3):281-287.

9. Javidfar J, Brodie D, Wang D, Ibrahimiye AN, Yang J, Zwischenberger JB, Sonett J, et al. Use of bicaval dual-lumen catheter for adult venovenous extracorporeal membrane oxygenation. Ann Thorac Surg. 2011;91(6):17631768; discussion 1769.

10. Wang D, Zhou X, Liu X, Sidor B, Lynch J, Zwischenberger JB. Wang-Zwische double lumen cannula-toward a percutaneous and ambulatory paracorporeal artificial lung. ASAIO J. 2008;54(6):606-611.

11. Mateen FJ, Muralidharan R, Shinohara RT, Parisi JE, Schears GJ, Wijdicks EF. Neurological injury in adults treated with extracorporeal membrane oxygenation. Arch Neurol. 2011;68(12):1543-1549.

12. Butt W, Maclaren G. Extracorporeal membrane oxygenation. F1000Prime Rep. 2013;5:55.

13. Schmidt M, Tachon G, Devilliers C, Muller G, Hekimian $\mathrm{G}$, Brechot N, Merceron S, et al. Blood oxygenation and decarboxylation determinants during venovenous ECMO for respiratory failure in adults. Intensive Care Med. 2013;39(5):838-846.

14. Chauhan S, Subin S. Extracorporeal membrane oxygenation, an anesthesiologist's perspective: physiology and principles. Part 1. Ann Card Anaesth. 2011;14(3):218229.

15. Sidebotham D, McGeorge A, McGuinness S, Edwards M, Willcox T, Beca J. Extracorporeal membrane oxygenation for treating severe cardiac and respiratory failure in adults: part 2-technical considerations. J Cardiothorac Vasc Anesth. 2010;24(1):164-172.

16. Practice parameters for determining brain death in adults (summary statement). The Quality Standards Subcommittee of the American Academy of Neurology. Neurology. 1995;45(5):1012-1014.

17. Wijdicks EF, Varelas PN, Gronseth GS, Greer DM. Evidence-based guideline update: determining brain death in adults: report of the Quality Standards Subcommittee of the American Academy of Neurology. Neurology. 2010;74(23):1911-1918.

18. Price MR, Galantowicz ME, Stolar CJ. Congenital diaphragmatic hernia, extracorporeal membrane oxygenation, and death: a spectrum of etiologies. J Pediatr Surg. 1991;26(9):1023-1026; discussion 1026-1027.

19. Muralidharan R, Mateen FJ, Shinohara RT, Schears GJ, Wijdicks EF. The challenges with brain death determination in adult patients on extracorporeal membrane oxygenation. Neurocrit Care. 2011;14(3):423-426.

20. Hsieh CE, Lin HC, Tsui YC, Lin PY, Lin KH, Chang YY, 
Chen YL. Extracorporeal membrane oxygenation support in potential organ donors for brain death determination. Transplant Proc. 2011;43(7):2495-2498.

21. Jarrah RJ, Ajizian SJ, Agarwal S, Copus SC, Nakagawa TA. Developing a standard method for apnea testing in the determination of brain death for patients on venoarterial extracorporeal membrane oxygenation: a pediatric case series. Pediatr Crit Care Med. 2014;15(2):e38-43.

22. Smilevitch P, Lonjaret L, Fourcade O, Geeraerts T. Apnea test for brain death determination in a patient on extracorporeal membrane oxygenation. Neurocrit Care. 2013;19(2):215-217.

23. Iannuzzi M., Marra A., Derobertis E., Servillo G. Apnea Test for Brain Death Diagnosis in a Patient on Extracor- poreal Membrane Oxygenation. Journal of Anesthesia \& Critical Care. 2014;1.

24. Hoskote SS, Fugate JE, Wijdicks EF. Performance of an apnea test for brain death determination in a patient receiving venoarterial extracorporeal membrane oxygenation. J Cardiothorac Vasc Anesth. 2014;28(4):1027-1029.

25. Goswami S, Evans A, Das B, Prager K, Sladen RN, Wagener G. Determination of brain death by apnea test adapted to extracorporeal cardiopulmonary resuscitation. J Cardiothorac Vasc Anesth. 2013;27(2):312-314.

26. Yang HY, Lin CY, Tsai YT, Lee CY, Tsai CS. Experience of heart transplantation from hemodynamically unstable brain-dead donors with extracorporeal support. Clin Transplant. 2012;26(5):792-796. 